\title{
MULTIKULTURALNA KOMUNIKACIJSKA STRATEGIJA
}

\author{
Ozren Rafajac \\ Dr. sc., docent, Veleučilište u Rijeci, Vukovarska 58, 51000 Rijeka, Hrvatska; \\ e-mail: ozren.rafajac@gmail.com \\ Sara Shanice Washington \\ Bacc. oec., studentica, Veleučilište u Rijeci, Vukovarska 58, 51000 Rijeka, Hrvatska; \\ e-mail: zasaru.wash@gmail.com
}

\section{SAŽETAK}

Ovim radom definiraju se smjernice u implementaciji multikulturalne komunikacijske strategije, kao i važnost te strategije za razvojjavni i privatnih organizacija u Republici Hrvatskoj. Analiza migracijskih, turističkih i izvoznih trendova jasno ukazuje da u Republici Hrvatskoj postoji snažna potreba za implementacijom multikulturalne komunikacijske strategije. Multikulturalna komunikacijska strategija predstavlja komunikacijski okvir koji omogućuje učinkovitu interakciju pripadnika različitih kultura. Tu je strategiju moguće opisati kao „master ključ" koji otvara više brava, od kojih svaka ima svoj vlastiti ključ. Multikulturalna komunikacijska strategija primarno se oslanja na konvergentne komunikacijske taktike. Da bi se implementirao takav oblik komunikacije preporučljivo je slijediti šest osnovnih smjernica, a to su: empatija, fleksibilnost, fokusiranost, višejezičnost, uključivost i interaktivnost. Empatija predstavlja sposobnost identifikacije osjećajnih stanja sugovornika, koja se poboljšava postavljanjem dubinskih pitanja i aktivnim slušanjem. Fleksibilnost podrazumijeva sposobnost prilagodbe, koja se ostvaruje kroz minimiziranje osobne pristranosti. Fokusiranost podrazumijeva osnaživanje primarno onih konverzacija koje olakšavaju suradnju. Osim kroz korištenje većeg broja jezika, višejezičnost se najlakše postiže slikama i simbolima koji su razumljivi većem broju ljudi, bez obzira na jezik kojim govore. Uključivost se najčešće provodi kroz sudjelovanje u donošenju relevantnih političkih i poslovnih odluka. Osim kroz digitalne komunikacijske kanale, interkativnost se ostvaruje i na sve ostale načine koji omogućuju razmjenu informacija s ciljnom skupinom korisnika. Multikulturalna komunikacija najlakše se realizira u situacijama u kojima postoji obostrana potreba za suradnjom i razumijevanjem. Osim u tržišno orijentiranim organizacijama, multikulturalnu komunikaciju potrebno je implementirati i u javnom sektoru, a naročito u područjima kao što su promet, zdravstvo, obrazovanje, zakonodavstvo i javna administracija.

Ključne riječi: poslovna komunikacija, multikulturalnost, interkulturalnost, multikulturalna komunikacijska strategija 


\section{UVOD}

U suvremenom društvu gotovo da i ne postoji uspješna poslovna organizacija koja nije suočena s izazovom multikulturalnosti u poslovnoj komunikaciji. Menadžeri čije tvrtke posluju međunarodnom tržištu, a čak i oni čije tvrtke posluju na lokalnom tržištu, sve češće su primorani razvijati multikulturalne komunikacijske vještine kako bi uspješno surađivali s pripadnicima različitih kultura. Među najvažnije čimbenike koji povećavaju potrebu za implementacijom multikulturalne komunikacijske strategije ubrajaju se sljedeći procesi: nastojanje da se proizvod i/ili usluga ponudi pripadnicima različitih kultura; snažne migracije stanovništva; niski i negativni prirast stanovništva koji zahtijeva uvoz stranih radnika; te visoka orijentiranost na turističke i prometne usluge. Navedeni čimbenici naročito su aktualni u Republici Hrvatskoj, a slične je procese moguće prepoznati i u ostalim zemljama Europske Unije. U kontekstu multikulturalne komunikacije, sve što vrijedi za glavne, odnosno dominantne kulture, vrijedi i za različite subkulture, budući da i jedne i druge obuhvaćaju skup normi, sustava vrijednosti i obrazaca ponašanja, koji razlikuju jednu grupu ljudi od neke šire grupe kojoj pripadaju. Žele li izbjeći potencijalne probleme i nerazumijevanje, organizacije koje vlastite proizvode odluče nuditi pripadnicima različitih kultura svakako bi trebale obučiti svoje djelatnike o specifičnim karakteristikama tih kultura. Dok su u prošlosti kulture diferencirane isključivo prema pripadnosti etničkim skupinama, nacijama, vjerskim obilježjima i jezicima, danas se kulture uglavnom promatraju u širem kontekstu, pa tako kad pričamo o multikulturalnosti, pripadnike jedne te iste kulture može povezivati prvenstveno životni i/ili glazbeni stil, a ne nužno i pripadnost istoj etničkoj skupini (npr. subkultura elektroničke glazbe).

Pred izazovom multikulturalne komunikacije ne nalazi se samo menadžer europskog brenda koji se nastoji probiti na kineskom tržištu, već i menadžer lokalnog restorana nekoliko ulica iza vaše kuće, koji osim komunikacije s osobljem, koje je najčešće sastavljeno od pojedinaca koji dolaze iz više različitih kulturnih okruženja, paralelno mora voditi računa o tome posjećuju li njegov restoran pripadnici različitih kultura i/ili subkultura. Ako je odgovor na prethodno pitanje potvrdan i/ili ako tek planira u svoj restoran privući neku specifičnu (sub)kulturnu skupinu ljudi, menadžer bi svakako trebao primijeniti multikulturalnu komunikacijsku strategiju, prilagoditi ponudu i obučiti svoje osoblje za prikladan način komunikacije s tom grupom ljudi. Kultura je fluidna kategorija koja se stalno mijenja i reprezentira kroz navike, običaje, stavove i ponašanja. lako su kulture promjenjive, te unatoč tome što se, pod utjecajem globalizacije i međusobnog suživota velikog broja pripadnika različitih kultura u metropolitskim središtima, svakodnevno redefiniraju, razlike među preferencijama i obrascima ponašanja pripadnika različitih kultura često su značajne, a samim time i bitan element u (poslovnoj) komunikaciji.

Suvremeno društvo karakteriziraju snažne turističke i ekonomske migracije, te rast međunarodne trgovine, a što izravno utječe na značajnost multikulturalne komunikacije. Baldwin i Hunt (2012) interkulturalnu komunikaciju definiraju kao komunikaciju u kojoj su kulturne razlike dovoljno velike da utječu na proizvodnju ili potrošnju, a nastoje je razlikovati od međugrupne komunikacije, koja se događa kada naša percepcija vlastitog ili tuđeg društvenog identiteta (npr. rase, regije, religije, itd.) utječe na komunikaciju, čak i ako nema stvarnih kulturnih razlika. Naglašavajući važnost vizualnog definiranja predodžbe o kulturi Wiggins (2012) koristi različite metafore kao 
što su metafora o ledenom brijegu, metafora o luku, genealoško stablo, podloga i kavez. Dok raspravlja o interkulturnoj komunikaciji Al-Araki (2015) koristi metaforu ruksaka i ljestvi, te zaključuje da su sve osobe potencijalno sposobne integrirati se u bilo koje društvo identifikacijom svojih ruksaka (koji se pune tijekom procesa socijalizacije) te revizijom vlastitih navika i mentalnih sklonosti putem ljestvi (koje se predstavljaju svojevrsne premise uspješne komunikacije). Kumbier i Schulz von Thun (2009) nude pregled metoda, modela i primjera za uspješnu komunikaciju između različitih svjetskih kultura u duhu sveopće globalizacije, dok Blanchard et al. (2013) ističu potrebu za integriranjem kulturnih razmatranja u sustave s umjetnom inteligencijom kako bi se poboljšale naše interakcije. Prema istraživanju Culture Wizard-a (2016) 68 \% ispitanika izjavljuje da su kulturni izazovi najveća prepreka produktivnosti globalnog virtualnog tima. lako je samo $18 \%$ ispitanika izjavilo da su njihove tvrtke izgubile poslovne prilike zbog kulturnih nesporazuma, broj propuštenih prilika vjerojatno je i veći od toga, a što jasno upućuje na ekonomski značaj ove teme (Culture Wizard, 2016).

I u Republici Hrvatskoj tema multikulturalnosti u posljednjih dvadeset godina postaje sve popularnija. Perasović (2002) tako ističe da svaka (kultura i/lii) subkultura posjeduje „simboličku strukturu" (slang, glazbu, stil odijevanja, simbole...), koju mnogi promatraju neovisno o pojedinačnim subjektima koji te stilove žive, pa je upravo zbog te „simboličke strukture“ moguće da pojedinci, a ne isključivo skupine, pripadaju različitim subkulturnim stilovima života iako ih ne prakticiraju u potpunosti njihova značenja. Na primjer, netko se može izjašnjavati kao vjernik iako rijetko ili pak uopće ne prakticira ideale te vjere. $\mathrm{Na}$ isti način, netko se može identificirati kao sportski tip osobe i kupovati sportsku odjeću iako se izuzetno rijetko ili uopće aktivno ne bavi sportom. Mesić (2006) identificira različite oblike multikulturalizma kao što su konzervativni, kritički, liberalni, lijevo-liberalni i fluidni multikulturalizam, te ističe nedostatke različitih pristupa pri čemu liberalni zaobilazi pitanje kompetencije različitih etničkih grupa, lijevo liberalni reificira i esencijalizira identitete, dok fluidni tretira etničke identitete kao da su opcionalni. Stričević (2012) pojam multikulturalnost definira kao ideal skladnog suživota kulturno različitih skupina u kontekstu ideje pluralnog društva. Zebec (2016) provodi empirijsko istraživanje kojim pronalazi da se većina ispitanika (90 \%) slaže ili se donekle slaže s time da su spremni izbjegavati stereotipe i predrasude u komunikaciji, dok Jagić (2006) provodi empirijsko istraživanjem kojim potvrđuje tezu da je turizam prvorazredni interkulturalni fenomen koji snažno promovira i stvara interkulturalni duh. lako se ovom temom do sada bavio prilično široki krug autora, relativno je mali broj dostupnih izvora koji nude praktične upute za oblikovanje multikulturalne komunikacijske strategije. Svrha i cilj ovog rada je postaviti smjernice u oblikovanju multikulturalne komunikacijske strategije, te analizirati značaj multikulturalnosti u društveno-ekonomskom razvoju Republike Hrvatske. Da bi se ostvario postavljeni cilj ovim radom nastoji se odgovoriti na sljedeća pitanja:

- Što je to multikulturalna komunikacijska strategija?

- Koliki je značaj multikulturalne komunikacije za Republiku Hrvatsku?

- Koje su praktične smjernice u implementaciji multikulturalne komunikacijske strategije?

Ovaj rad namijenjen je svima koji žele unaprijediti vještinu komunikacije u multikulturalnim okruženjima, a naročito studentima ekonomskih usmjerenja i menadžerima suvremenih poduzeća 
koji bi rješenja ponuđena u ovom radu mogli i trebali koristiti u unapređenju konkurentnosti i senzibilnosti vlastitih organizacija. Osnovna hipoteza provedenog istraživanja je da organizacijekoje posluju na tržištu Republike Hrvatske imaju snažnu potrebu za implementacijom multikulturalne komunikacijske strategije. Prihvaćanje i uvažavanje kulturoloških razlika, otvara novi prostor za dijalog i suradnju koja ne bi bila ostvarena među grupama i/ili pojedincima koji negiraju i/ili nisko vrednuju multikulturalnost.

\section{METODOLOGIJA}

Multikulturna komunikacija se događa kad su pripadnici jedne kulture u nekoj vrsti interakcije s pripadnicima druge kulture. Komunikacija se odvija verbalnim i neverbalnim putem, što znači da pri upoznavanju nama strane kulture moramo učiti i o značenju izraza lica, tonu glasa kojim se govori, tjelesnim pokretima i gestama prilikom komunikacije, osobnom prostoru među sugovornicima i još nizu važnih neverbalnih simbola i običaja druge kulture kako bismo ostvarili što bolju komunikaciju i razumijevanje. U situacijama kad nastoje komunicirati s nekim tko ne dijeli njihove norme, stavove i pravila ponašanja, pojedinci su primorani uložiti dodatnu energiju za učenje i prilagodbu, pri čemu redefiniraju vlastite stavove i obrasce ponašanja, a to nije uvijek jednostavno i ugodno. Kompleksnost se dodatno povećava kad želimo istovremeno komunicirati s većim brojem pripadnika različitih kultura. Multikulturalna komunikacijska strategija predstavlja komunikacijski okvir oblikovan na temelju preporuka koje omogućuju istovremenu interakciju s većim brojem pripadnika različitih kultura. Provedeno istraživanje oslanja se na komunikacijsko adaptivnu teoriju (engl. Communication Adaptation Theory - CAT) koja se zasniva na vezama između jezika, konteksta i identiteta (Giles, Ogay, 2007), te na Hallovu teoriju interkulturalne komunikacije koja razlikuje kulture visokog i niskog konteksta (Hall, 1990). Komunikacija u kulturi visokog konteksta može biti prilično zahtjevna za osobu koja ne razumije "nepisana pravila" kulture u kojoj se vrlo malo toga uzima "zdravo za gotovo". Istodobno, u kulturi s niskim kontekstom najčešće ne postoje dodatna, odnosno "skrivena" značenja . lako nastoji biti fleksibilna na način da korisnicima koji to traže nudi dodatna objašnjenja, strategija multikulturalne komunikacije preferira okruženje niskog konteksta, budući da to umanjuje šanse za nesporazum. Prema komunikacijsko adaptivnoj teoriji, osim što komunikatori svoj stil komunikacije često prilagođavaju publici, odnosno pojedincu, grupi ili društvu općenito, način na koji se komunikacija odvija snažno je povezan s kontekstom i pozicijama moći. lako kritičari s pravom upozoravaju na opasnost pretjeranog redukcionizma, te na opasnu pretpostavku racionalnosti (jer ljudi nisu uvijek racionalni, nego samo onda kad to odluče biti), ova teorija podrazumijeva da postoje dva osnovna procesa u komunikaciji, a to su: konvergencija i divergencija. Konvergencija predstavlja proces kroz koji pojedinac prilagođava komunikacijske obrasce $u$ interakciji tako da oni više sliče govornim obrascima njihove publike, dok se divergencija odnosi na postupke i strategije kojima komunikatori nastoje istaknuti razlike između sebe i onih s kojima komuniciraju. Multikulturalna komunikacijska strategija primarno se oslanja na konvergentne taktike, dok divergentne taktike koristi daleko rjeđe, a najčešće samo onda kad ih odluče koristiti naši sugovornici. Primjenom različitih znanstvenih metoda kao što su metoda analize, sinteze, deskripcije i metoda sustavnog mišljenja nastoji se pronaći odgovor na to kako oblikovati učinkovitu multikulturalnu komunikacijsku strategiju. Sustavno mišljenje je univerzalno primjenjivi okvir za pronalaženje suptilnih međuovisnosti i veza između elemenata 
u kompleksnim sustavima koji olakšava upravljanje i djelovanje u skladu s prirodnim procesima društveno-ekonomskog okruženja (Senge, 2010). Osim analize društvenih kretanja koji ukazuju na značaj multikulturalne komunikacije za Republiku Hrvatsku, autori predlažu originalne i univerazlno primjenjive strateške smjernice za implementaciju multikulturalne komunikacijske strategije.

\section{ANALIZA TRENDOVA KOJI UKAZUJU NA ZNAČAJ MULTIKULTURALNE KOMUNIKACIJE U REPUBLICI HRVATSKOJ}

Migracije tj. kretanja stanovništva imaju dvije osnovne sastavnice: imigraciju i emigraciju. Pojam imigracije objašnjava useljavanje na određeno područje dok emigracija označava iseljavanje. lako u nekim prenapučenim sredinama može vrijediti i obratno, imigracija iz ekonomske perspektive najčešće predstavlja pozitivnu oznaku ukupnog kretanja stanovništva budući da povećava dostupnost radne snage i bogatstvo ponude, a smanjuje cijenu rada. Emigracija, s druge strane, iz ekonomske perspektive se najčešće promatra kao negativni proces u kretanju stanovništva koji dovodi do smanjenja dostupne radne snage i ponude, te do povećanja cijene rada. Kada se promatra razlika između broja useljenih i iseljenih iz određene zemlje u određenom razdoblju, ta se razlika naziva migracijski saldo ili migracijska bilanca. Ako je broj imigriranih veći od broja emigriranih tada je migracijski saldo pozitivan, a ako je broj emigriranih veći od broja imigriranih imamo negativan migracijski saldo. O nultom migracijskom saldu ili ravnotežnoj migracijskoj bilanci govorimo kada se izjednači broj imigriranog i emigriranog stanovništva (Wertheimer-Beletić, 1999.).

Tablica 1. Migracije stanovništva Republike Hrvatske od 2015. do 2019. godine

\begin{tabular}{|c|c|c|c|c|c|}
\hline & 2015. & 2016. & 2017. & 2018. & 2019. \\
\hline Doseljeni iz inozemstva & 11.706 & 13.985 & 15.553 & 26.029 & 37.726 \\
\hline Odseljeni u inozemstvo & 29.651 & 36.436 & 47.352 & 39.515 & 40.148 \\
\hline Migracijski saldo & -17.945 & -22.451 & -31.799 & -13.486 & -2.422 \\
\hline
\end{tabular}

Prema podacima iz tablice 1, Republika Hrvatska je u promatranom razdoblju od 2015. do 2019. godine imala kontinuirani negativni migracijski saldo koji je nešto ublažen tek u 2019. godini. U razdoblju od 2015. do 2019. godine iz Republike Hrvatske u inozemstvo se odselilo 193.102 osoba, dok se u istom razdoblju iz inozemstva doselilo 104.999 osoba, što čini ukupan migracijski saldo od -88.103 osoba. Trenutni demografski trendovi vrlo se negativno odražavaju na gospodarstvo Republike Hrvatske. Prirodni je prirast na nacionalnoj razini negativan od 1998. godine, a u posljednjim godinama sve je snažnije naglašen, pa je tako u 2017. godini bio je negativno rekordan sa 16,9 tisuća više umrlih od živorođenih (HGK, 2019). Nastave li se negativni demokratski trenovi Republika Hrvatska će do 2051. godine izgubiti čak četvrtinu današnjeg stanovništva (vidi grafikon 1). 
Grafikon 1. Broj stanovnika Republike Hrvatske, demografske projekcije do 2051. godine

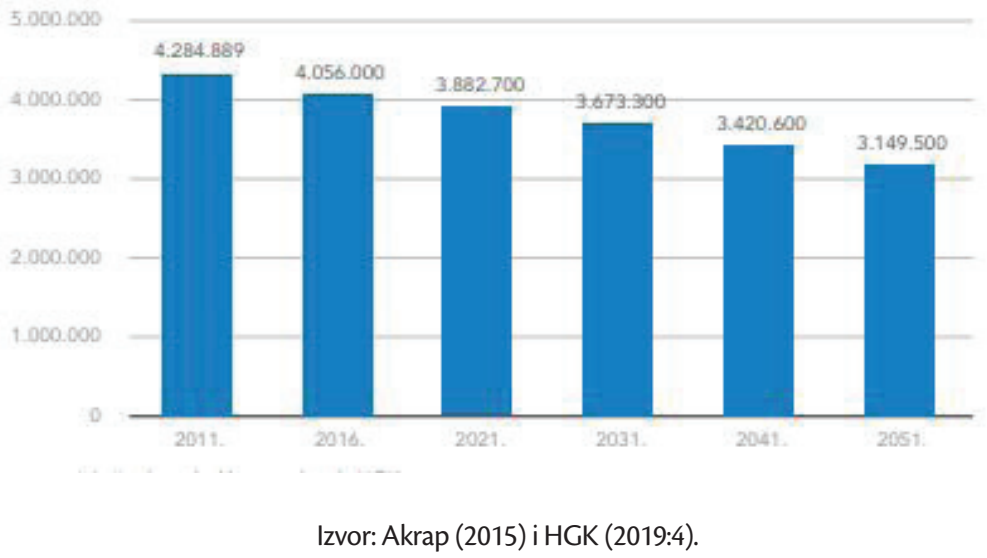

Kao što je vidljivo u tablici 2, u Republiku Hrvatsku u 2019. godini je iz inozemstva doselilo 37.726 osoba. Raznolikost u dobi doseljenog stanovništva potvrđuje potrebu za razvojem multikulturalnosti u svim sferama našeg društveno-ekonomskog okruženja.

Tablica 2. Broj doseljenih stanovnika iz inozemstva u Republiku Hrvatsku prema starosti i spolu u 2019. godini

\begin{tabular}{|c|c|c|c|}
\hline Dob & Ukupno & Muškarci & Žene \\
\hline $0-4$ & 559 & 285 & 274 \\
\hline $5-9$ & 411 & 201 & 210 \\
\hline $10-14$ & 326 & 179 & 147 \\
\hline $15-19$ & 1.414 & 1.029 & 385 \\
\hline $20-24$ & 5.061 & 3.944 & 1.117 \\
\hline $25-29$ & 5.412 & 4.257 & 1.155 \\
\hline $30-34$ & 5.118 & 4.218 & 900 \\
\hline $35-39$ & 4.667 & 3.908 & 759 \\
\hline $40-44$ & 3.991 & 3.281 & 710 \\
\hline $45-49$ & 3.348 & 2.715 & 633 \\
\hline $50-54$ & 2.525 & 1.986 & 539 \\
\hline $55-59$ & 1.692 & 1.268 & 424 \\
\hline $60-64$ & 1.188 & 748 & 440 \\
\hline $65-69$ & 944 & 539 & 405 \\
\hline $70-74$ & 488 & 294 & 194 \\
\hline 75 i više & 582 & 295 & 287 \\
\hline Ukupno & 37.726 & $\mathbf{2 9 . 1 4 7}$ & $\mathbf{8 . 5 7 9}$ \\
\hline
\end{tabular}


Podaci u tablicama 1. u 2. jasno ukazuju na potrebu za implementacijom multikulturalne komunikacijske strategije, ne samo u privatnom veći u javnom sektoru. Osim u tržišno orijentiranim organizacijama, multikulturalnu komunikacijsku strategiju potrebno je implementirati u svim ostalim segmentima našeg društveno-ekonomskog okruženja, kao što su javni promet, zdravstvo, obrazovanje i javne administracija. Prikazani podaci ukazuju na rast priljeva stanovništva istočnih kultura, a naročito iz Azije što također upućuje na potrebu za implementacijom multikulturalne komunikacijske strategije.

Tablica 3. Pregled doseljenog stanovništva u RH od 2015. - 2019. godine prema geografskim regijama iz kojih osobe dolaze

\begin{tabular}{|l|c|c|c|c|c|c|}
\hline Regija & 2015. & 2016. & 2017. & 2018. & 2019. & $\begin{array}{c}\text { Ukupno u } \\
\text { promatranom } \\
\text { razdoblju }\end{array}$ \\
\hline Europa & - & - & - & - & - & \\
\hline Europska unija & 4.382 & 5.555 & 5.860 & 6.256 & 7.644 & 29.697 \\
\hline Ostale europske zemlje & 6.133 & 7.077 & 7.739 & 17.515 & 25.309 & 63.773 \\
\hline Azija & 475 & 447 & 419 & 903 & 3.113 & 5.357 \\
\hline Afrika & 118 & 92 & 87 & 128 & 175 & 600 \\
\hline Sjeverna i Srednja & 310 & 506 & 424 & 486 & 568 & 2.294 \\
Amerika & 82 & 83 & 109 & 125 & 181 & 580 \\
\hline Južna Amerika & 131 & 135 & 150 & 197 & 230 & 843 \\
\hline Oceanija & 75 & 90 & 765 & 419 & 506 & 1.855 \\
\hline Nepoznato & & Izvor: DZS (2020) & & & \\
\hline
\end{tabular}

Kako je i vidljivo u tablici 4, osim samog povećanja broja godišnjih kvota dozvola javila se i potreba za diversifikacijom vrsta samih dozvola. Tako se u 2018. i 2019. godini pojavila potreba za uvrštavanjem novih kvota za potrebe premještaja unutar društva i provedbu strateških investicijskih projekata, a što je izravna posljedica globalizacije, sve većeg otvaranja tržišta Republike Hrvatske, te povećanja stranih investicija. Uz utvrđene godišnje kvote dozvola za zapošljavanje stranaca, u praksi se koriste i dozvole za zapošljavanje stranaca izvan dozvoljenih godišnjih kvota. Te se dozvole izdaju ako neka organizacija zatraži dozvolu za zapošljavanje osobe u djelatnosti koja nije navedene u Odluci o godišnjoj kvoti dozvola za tu kalendarsku godinu. 
Tablica 4. Kvote dozvola za zapošljavanje stranaca u RH od 2015. - 2019. godine

\begin{tabular}{|c|c|c|c|c|c|c|}
\hline Godina & $\begin{array}{c}\text { Ukupna } \\
\text { godišnja } \\
\text { kvota } \\
\text { dozvola za } \\
\text { zapošljavanje } \\
\text { stranaca }\end{array}$ & $\begin{array}{c}\text { Godišnja } \\
\text { kvota za } \\
\text { produženje } \\
\text { već izdanih } \\
\text { dozvola za } \\
\text { zapošljavanje } \\
\text { stranaca }\end{array}$ & $\begin{array}{c}\text { Godišnja } \\
\text { kvota dozvola } \\
\text { za novo } \\
\text { ztranackavanje }\end{array}$ & $\begin{array}{c}\text { Godišnja } \\
\text { kvota } \\
\text { dozvola } \\
\text { za } \\
\text { sezonski } \\
\text { rad }\end{array}$ & $\begin{array}{c}\text { Godišnja } \\
\text { kvota } \\
\text { dozvola } \\
\text { za osobe } \\
\text { premještene } \\
\text { unutar } \\
\text { društva }\end{array}$ & $\begin{array}{c}\text { Godišnja } \\
\text { kvota } \\
\text { dozvola za } \\
\text { provedbu } \\
\text { strateških } \\
\text { investicijskih } \\
\text { projekata }\end{array}$ \\
\hline 2015. & 1.730 & 1.500 & 215 & 15 & - & - \\
\hline 2016. & 3.115 & 800 & 2.300 & 15 & - & - \\
\hline 2017. & 7.026 & 1.800 & 5.211 & 15 & - & - \\
\hline 2018. & 31.000 & 9.000 & 21.210 & 540 & 250 & - \\
\hline 2019. & 65.100 & 15.000 & 41.810 & 6.540 & 250 & 1.500 \\
\hline
\end{tabular}

U tablici 5 prikazan je broj ukupno izdanih dozvola za zapošljavanje stranaca u promatranom razdoblju od 2015. do 2019. godine. Prikazani podaci nedvojbeno ukazuju na to da se slika stanovništva u Republici Hrvatskoj značajno mijenja, a što zahtijeva strateške promjene u organizaciji i komunikaciji, odnosno veću senzibilizaciju društva prema multikulturalnosti.

Tablica 5. Izdane dozvole za rad od 2015. - 2019. godine

\begin{tabular}{|c|c|c|}
\hline Godina & Ukupno izdano dozvola za zapošljavanje stranaca & Godišnje povećanje (\%) \\
\hline 2015. & 2.563 & - \\
\hline 2016. & 3.399 & $32,62 \%$ \\
\hline 2017. & 7.400 & $117,71 \%$ \\
\hline 2018. & 20.769 & $180,66 \%$ \\
\hline 2019. & 49.317 & $137,45 \%$ \\
\hline
\end{tabular}

Snažna orijentacija hrvatskog gospodarstva na turizam dodatni je moment koji osnažuje navedenu potrebu. Na grafikonu 2 vidljivo je da su Republici Hrvatskoj 2017. i 2018. godine najveći broj noćenja ostvarili turisti iz Njemačke, Slovenije i Austrije. Broj pripadnika različitih kultura (i subkultura) koji turistički posjećuju našu zemlju stalno se povećava, a da bi privukli goste različitih kultura potrebno je detaljnije proučiti njihove kulturne obrasce i preferencije, te u skladu s time oblikovati ponudu. Jedan od primjera takve prilagodba jest implementacija Halal certifikata koji turistima omogućuje održavanje vjerskih obreda i pripremu prilagođene prehrane. Budući da muslimani predstavljaju gotovo jednu četvrtinu ukupne svjetske populacije, prema procjenama stručnjaka svjetsko halal turističko tržište u 2017. vrijedilo je čak 160 milijardi USD (Dugonjić, 2018). 
Grafikon 2. Noćenja stranih turista prema zemlji prebivališta koji su u 2017. i 2018. godini posjetili Republiku Hrvatsku

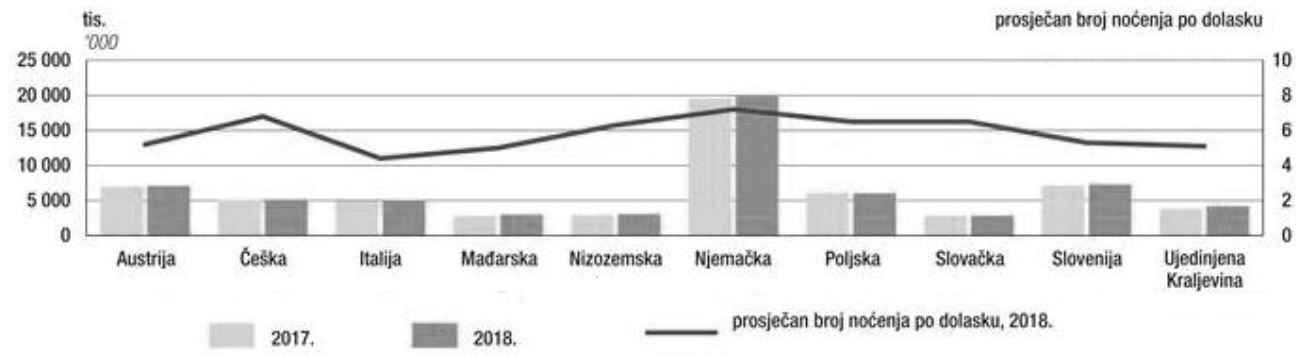

Izvor: DZS (2019a)

Implementacija multikulturalne komunikacije naročito je važna prilikom oblikovanja proizvoda i usluga koje se nastoji plasirati na inozemna tržišta, a što često podrazumijeva i komunikaciju s pripadnicima drugih kultura.

Tablica 6. Izvoz RH u tisućama kuna u 2017. i 2018. godini prema ekonomskim grupacijama

\begin{tabular}{|l|c|c|c|}
\hline & 2017. & 2018. & Index (2018 / 2017) \\
\hline Ukupno & 104600956 & 107913440 & 103,2 \\
\hline Države članice EU-a & 67866858 & 74188818 & 109,3 \\
\hline Zemlje Efte & 1700313 & 1905308 & 112,1 \\
\hline Zemlje Cefte & 18234030 & 18185221 & 99,7 \\
\hline Zemlje OPEC-a & 1604236 & 1795565 & 111,9 \\
\hline Ostale europske zemlje & 3590098 & 3293047 & 91,7 \\
\hline Ostale azijske zemlje & 3566873 & 3737799 & 104,8 \\
\hline Ostale afričke zemlje & 2212041 & 1088032 & 49,2 \\
\hline Ostale američke zemlje & 5448867 & 3461899 & 63,5 \\
\hline Oceanijske zemlje & 265219 & 149288 & 56,3 \\
\hline Neraspoređeno & 112421 & 108464 & 96,5 \\
\hline
\end{tabular}

Prema podacima u tablici 6. Republika Hrvatska najviše izvozi u zemlje EU i zemlje Cefte koje obuhvaćaju Bosnu i Hercegovinu, Srbiju, Crnu Goru, Albaniju, Sjevernu Makedoniju i Moldaviju. U zemlje Efte izvoz se u promatranom razdoblju povećao za $12.1 \%$, a od toga najviše u Island, Švicarsku i Norvešku. U zemlje Europske Unije, u promatranom razdoblju izvoz je porastao za 9.3 \%, a od toga najviše u Rumunjsku i Finsku. U zemlje OPEC-a izvoz se ukupno povećao za $11.9 \%$, a od toga se naročito povećao izvoz u Irak, Kongo i Nigeriju. U azijskim zemljame od 2017. do 2018. godine izvoz se povećao za ukupno $4.8 \%$, a od toga naročito u Libanon, Tajland i Filipine. 


\section{RASPRAVA}

Nema dvojbe da kultura utječe na komunikaciju, a da oboje mogu utjecati i na organizacijske procese. Otvaranje novim tržištima i ulagačima, te sve veći broj stranih radnika u Republici Hrvatskoj jasni su pokazatelji da se naše društvo mijenja. Republika Hrvatska relativno je mala zemlja koja zbog demografskih i ekonomskih karakteristika nema drugog izbora nego biti otvorena prema suradnji s pripadnicima drugih kultura. Upravo stoga od velike je važnosti da kao društvo počnemo prihvaćati promjene, te da krenemo prilagođavati vlastite komunikacijske strategije novim izazovima. Da bi u tome bili uspješni, moramo učiti o drugim kulturama, te razumjeti i prihvatiti razlike kao nešto pozitivno što nam može pomoći u društveno-ekonomskom razvoju. Sve industrije ili sektori, pa čak i oni koji su donedavno bili primarno usmjereni na lokalno tržište i kulturu, poput obrazovanja, u budućnosti bi trebali biti sposobni prilagođavati vlastite proizvode $i$ usluge različitim kulturama i tržištima. Snažan priljev stranih radnika, pojačana imigracija, kao i sve snažnija nastojanja za izvozom lokalnih proizvoda i usluga na međunarodna tržišta, navode javne i privatne organizacije u Republici Hrvatskoj da se suoče s izazovima multikulturalnosti. Neki od najboljih pristupa u razvoju multikulturalnog okruženja su aktivni rad na ublažavanju kulturalnih barijera (npr. zapošljavanje pripadnika različitih kultura), učenje o stranim kulturama (npr. čitanje literature i posjeti stranoj kulturi) i implementacija multikulturalne komunikacijske strategije koja će olakšati komunikaciju i suradnju s pripadnicima različitih kultura. Unatoč tome što se širenjem spoznaja specifičnoj kulturi može unaprijediti komunikaciju i suradnju s pripadnicima te kulture o kojoj smo nešto više naučili, kompleksnost se dodatno povećava kada nastojimo istovremeno surađivati i komunicirati s većim brojem pripadnika različitih kultura. Da bi supješno poslovali na međunarodnom tržištu i/lili surađivali s pripadnicima drugih kultura u multikulturalnim timovima potrebno je primijeniti multikulturalnu komunikacijsku strategiju.

U praksi postoji više vrsta komunikacijskih strategija, od onih koje se primjenjuju u komunikaciji u „četiri oka“ do onih koje omogućuju plasman proizvoda na međunarodno tržište. Komunikacijska strategija koju koriste suvremene organizacije temelji se na viziji, misiji i vrijednostima organizacije, na specifičnim ciljevima (vidljivost u zajednici, javna podrška, financijska dobit,..), te na raspoloživim resursima (npr. financijske mogućnosti i tehnologija). Komunikacijska strategija predstavlja unaprijed definirani obrazac u struji odluka kojim se definira ciljeve komunikacije, ciljne skupine kojima se obraćamo i komunikacijske kanale koje koristimo. Komunikacijskom strategijom organizacija prenosi svoju osnovnu poruku zajednici u kojoj djeluje. Interkulturalna komunikacija podrazumijeva interakciju između dvaju ili više pripadnika različitih (sub)kultura, koja omogućuje nadvladavanje (sub)kulturnih barijera (Auwalu Issa et al., 2015). Interkulturalnu komunikaciju moguće je promatrati kao komunikaciju koja se odvija u interkulturalnom simboličkom okruženju (Arasaratnam, 2013:48). Prema Lustigu i Koesteru (2007:46) interkulturnu komunikaciju je moguće definirati kao simbolički, interpretativni, transakcijski i kontekstualni proces u kojem ljudi iz različitih kultura stvaraju zajednička značenja. Multikulturalna komunikacijska strategija predstavlja specifičan komunikacijski okvir koji omogućuje istovremenu učinkovitu interakciju pripadnika različitih kultura. To je radni i komunikacijski okvir koji smanjuje probleme koji mogu nastati u komunikaciji s pripadnicima različitih kultura. Primjenom predloženog komunikacijskog okvira, organizacije i pojedinci postaju uspješniji u komunikaciji unutar multikulturalnog okruženja. 
Sama činjenica da neka organizacija svoju komunikacijsku strategiju nije prilagodila pripadnicima neke specifične kulture, smanjuje njezinu šansu za suradnjom i trgovinskom razmjenom s tom kulturom. Budući da su suradnja i trgovinska razmjena put općeg društvenog razvoja, koristi od implementacije multikulturalna komunikacijske strategije trebali bi imati sve poslovne i javne organizacije u Republici Hrvatskoj. U tablici 7 prikazane su smjernice u implementaciji multikulturalne komunikacijske strategije.

Tablica 7. Šest smjernica u implementaciji multikulturalne komunikacijske strategije

\begin{tabular}{|c|c|c|c|}
\hline PROBLEMI & PREDUVJETI & SMJERNICE & $\begin{array}{c}\text { KOMPLEKSNI } \\
\text { FAKTORI }\end{array}$ \\
\hline $\begin{array}{l}\text { - } \begin{array}{l}\text { Ne poznajemo } \\
\text { kulturu osobe } \\
\text { i/ili grupe }\end{array} \\
\text { Nesporazum } \\
\text { proizlazi zbog } \\
\text { razlika u } \\
\text { komuniciranju }\end{array}$ & $\begin{array}{ll}\text { - } & \text { Zainteresiranost } \\
\text { - } & \text { za sugovornika } \\
\text { i postavljanje } \\
\text { dubinskih pitanja }\end{array}$ & EMPATIJA & $\begin{array}{l}\text { - Sugovornici su iz } \\
\text { zatvorene kulture } \\
\text { - } \quad \text { Sugovornici koriste } \\
\text { kulturu koja je } \\
\text { bitno različita od } \\
\text { naše }\end{array}$ \\
\hline $\begin{array}{ll}\text { - } & \text { Primjenjujemo } \\
\text { samo } \\
\text { jedan kanal } \\
\text { komunikacije } \\
\text { - } \quad \text { Nismo } \\
\text { sposobni } \\
\text { ublažiti odlike } \\
\text { vlastitog stila } \\
\text { - } \quad \text { komunikacije }\end{array}$ & $\begin{array}{ll}\text { - } & \text { Postojanje više } \\
\text { komunikacijskih } \\
\text { - } & \text { kanala } \\
\text { - } & \text { Ublažavanje odlika } \\
\text { vlastitog } \\
\text { - } & \text { stila komunikacije }\end{array}$ & FLEKSIBILNOST & $\begin{array}{l}\text { - } \begin{array}{l}\text { Sugovornici su } \\
\text { članovi kulture } \\
\text { visokog konteksta }\end{array} \\
\text { - } \quad \text { Komunikacija s } \\
\text { osobama čiji se } \\
\text { komunikacijski stil } \\
\text { razlikuje od našeg }\end{array}$ \\
\hline $\begin{array}{l}\text { - Sugovornici } \\
\text { ne žele } \\
\text { komunicirati o } \\
\text { nekoj temi } \\
\text { - Nepostojanje } \\
\text { plana i jasnog } \\
\text { cilja }\end{array}$ & $\begin{array}{l}\text { - Jasna ideja o tome } \\
\text { što želimo postići } \\
\text { - Interes sugovornika }\end{array}$ & FOKUSIRANOST & $\begin{array}{l}\text { - } \begin{array}{l}\text { Sugovornici } \\
\text { koriste preširoka } \\
\text { objašnjenja }\end{array} \\
\text { - Sugovornici nisu } \\
\text { zainteresirani za } \\
\text { temu }\end{array}$ \\
\hline $\begin{array}{l}\text { - Sugovornik } \\
\text { ne govori } \\
\text { niti jedan od } \\
\text { ponuđenih } \\
\text { jezika } \\
\text { - Ne poznajemo } \\
\text { jezik } \\
\text { sugovornika }\end{array}$ & $\begin{array}{ll}\text { - } & \text { Prevedeni materijali } \\
\text { i upute } \\
\text { - } \quad \text { Koristimo } \\
\text { se jezikom i } \\
\text { simbolima koji } \\
\text { ciljana publika } \\
\text { razumije }\end{array}$ & VIŠEJEZIČNOST & $\begin{array}{l}\text { - Sugovornik loše } \\
\text { govori jezik kojim } \\
\text { komuniciramo }\end{array}$ \\
\hline
\end{tabular}




\begin{tabular}{|c|c|c|c|}
\hline $\begin{array}{ll}\text { - } & \text { Isključivi } \\
\text { pogled na } \\
\text { svijet u kojem } \\
\text { nema mjesta } \\
\text { za drugačije } \\
\text { mišljenje }\end{array}$ & $\begin{array}{l}\text { - Uvjerenje o tome } \\
\text { da su različitosti dio } \\
\text { cjeline } \\
\text { - Poštivanje } \\
\text { razlika, budući da } \\
\text { perspektiva utječe } \\
\text { na naše stavove i } \\
\text { odluke }\end{array}$ & UKLJUČIVOST & $\begin{array}{ll}\text { - } & \text { Sugovornici dolaze } \\
\text { iz kultura koje su } \\
\text { bile ili su još uvijek } \\
\text { u sukobu } \\
\text { - } \quad \text { Komunikacija se } \\
\text { odvija u zatvorenoj } \\
\text { sredini }\end{array}$ \\
\hline $\begin{array}{l}\text { - Korisničko } \\
\text { sučelje je } \\
\text { suviše složeno } \\
\text { za razmjenu } \\
\text { informacije } \\
\text { - Niska razina } \\
\text { personalizacije } \\
\text { i prilagodbe } \\
\text { korisniku }\end{array}$ & $\begin{array}{l}\text { - Sugovornik koristi } \\
\text { komunikacijski } \\
\text { kanal kojim želimo } \\
\text { komunicirati (npr. } \\
\text { mobilne aplikacije) } \\
\text { Koristimo sve } \\
\text { dostupne kanale } \\
\text { komunikacije }\end{array}$ & INTERAKTIVNOST & $\begin{array}{l}\text { - Sugovornici imaju } \\
\text { nisku razinu } \\
\text { znanja u korištenju } \\
\text { naprednih } \\
\text { tehnologija } \\
\text { - Korisnicima } \\
\text { su naši kanali } \\
\text { komunikacije teško } \\
\text { dostupni }\end{array}$ \\
\hline
\end{tabular}

Empatija predstavlja sposobnost identifikacije osjećanih stanja naših sugovornika, a podrazumijeva iskrenu zainteresiranost za sugovornike koja se unapređuje postavljanjem dubinskih pitanja i aktivnim slušanjem. Multikulturalna komunikacijska strategija nastoji svima pružiti priliku da se predstave kako bi se lakše identificiralo njihove preferencije i navike. Čaki prije nego se pripadnicima različitih kultura odlučite postaviti dubinska pitanja koja otkrivaju njihove preferencije i navike, pobrinite se da saznate barem osnovne informacije o pripadnicima različitih kultura i subkultura s kojima nastojite komunicirati. Postavljanje dubinskih pitanja koja olakšavaju razumijevanje sugovornika i izbjegavanje „kulturoloških pogreški“ najčešće se tumači kao pozitivno nastojanje koje unapređuje komunikaciju. Kad se želi saznati specifične informacije o sugovornicima, dobro je unaprijed pripremiti specifični set pitanja, odnosno metode i tehnike (npr. simboli, mobilne aplikacije, upitnici) koje će olakšati upoznavanje i razmjenu informacija. Aktivnim slušanjem, koje podrazumijeva postavljanje većeg broja podpitanja, te analizom prikupljenih informacija moguće je značajno unaprijediti međusobno razumijevanje, te otkriti prilike za unapređenje suradnje koje ne bismo otkrili bez da smo takva pitanja postavili. lako ideje i stajališta sugovornika mogu biti suprotstavljena našima, važno je razumjeti da takve spoznaje unapređuju ukupnu kvalitetu odnosa i spoznaje o specifičnoj temi koje kasnije možemo iskoristiti u nekoj drugoj prilici. Empatija s pripadnicima različitih kultura, podrazumijeva i kreiranje jasnih i lako razumljivih poruka i uputa koje olakšavaju prilagodbu.

Fleksibilnost podrazumijeva sposobnost prilagodbe, koja se ostvaruje kroz minimiziranje osobne pristranosti. Na osobnoj razini svi bismo trebali biti spremni prepoznati vlastite pristranosti i pretpostavkekojeutječunatokakokomuniciramosdrugima.Sposobnostprilagodbesugovornicima omogućuje razmjenu informacija bez obzira na kulturne vrijednosti, norme i ponašanja koje se mogu razlikovati među publikom (Stobierski, 2019). Osobe iz kultura šireg konteksta žele i 
trebaju više vremena kako bi upoznali sugovornika i donijeli odluku. $\bigcup$ kulturama užeg konteksta pojedinci ulažu nešto manje vremena na upoznavanje i relativno brzo donose odluke. Ukoliko se ne primjenjuje fleksibilnost u količini dostupnih informacija i vremenu dostupnom za donošenje odluka, prilikom komunikacije članova kulture užeg konteksta i članova kulture šireg konteksta lako može doći do nesporazuma jer jedni drugima mogu biti nerazumljivi. Dok će jedni željeti provesti vrijeme sa sugovornikom, drugi će nastojati što je moguće prije prijeći na bit komunikacije. U toj se situaciji i jedni i drugi mogu osjećati uvrijeđeno. Dok jedni smatraju da im sugovornik troši dragocjeno vrijeme i zanima se za osobne detalje o sugovorniku, drugi smatraju da je direktan pristup nepristojan ili da je sugovornik pretjerano suzdržan. Multikulturalna komunikacijska strategija omogućuje fleksibilnost korištenjem većeg broja različitih komunikacijskih kanala (email, telefon, mobilna aplikacija, web, sastanci u živo), susprezanjem karakteristika osobnog komunikacijskog stila (na opće prihvatljivu razinu) te pružanjem osnovnih sažetih informacija i poveznica na detaljnije informacije, a što sugovornicima omogućuje brzo ili sporo donošenje odluka ovisno o njihovim osobnim preferencijama.

Fokusiranost podrazumijeva osnaživanje primarno onih konverzacija koje olakšavaju suradnju. Kad organizacija ima jasnu predodžbu o tome što komunikacijom želi postići, te ako uspije pridobiti pažnju sugovornika, puno je manja vjerojatnost da će doći do nesporazuma. lako razgovor o širem rasponu tema može omogućiti višu razinu svjesnosti o različitim kulturnim obrascima, normama i vrijednostima, u multikulturalnoj komunikaciji gubitak fokusa predstavlja vrlo sklizak teren. Neke teme zahtijevaju široka objašnjenja, koja često oduzimaju previše vremena, a time se potencijalno umara sugovornike, te potencira rasprave koje troše vrijeme i energiju koja je mogla biti uložena u neku drugu važniju aktivnost. Upravo stoga, kad organizacije nastoje komunicirati s većim brojem pripadnika različitih kultura, najbolje je zadržati fokusiranost na osnovne ciljeve komunikacije.

Višejezičnost omogućuje lakše razumijevanje među pripadnicima različitih kultura koje govore različitim jezikom. lako nije uvijek slučaj da pripadnici različitih kultura govore različitim jezikom, težnja da se sadržaj ponude sugovornicima na njihovom (materinjem) jeziku vrlo je važan dio multikulturalne komunikacijske strategije. Čak i kad se služe stranim jezicima, ljudima je daleko lakše komunicirati na njihovom prvom jeziku. To potvrđuju empirijska istraživanja prema kojima 9 od 10 internet korisnika kojima engleski jezik nije prvi jezik, radije posjećuju internet stranice na svom prvom jeziku, dok ih samo 53 \% izjavljuje da su spremni koristiti i englesku verziju stranice, ako nije dostupna ona na njihovom jeziku (Gallup, 2011:5). Da bi u većoj mjeri privukli kvalificirane ljudske potencijale iz strateških djelatnosti, te turiste i investitore koji dolaze iz ostalih kultura u Republici Hrvatskoj je potrebno ponuditi širi spektar obavijesti i uputa na stranim jezicima, te redizajnirati obrazovni proces na način da bude bolje prilagođen pripadnicima različitih kultura koje nastojimo pridobiti za život, rad i boravak u našoj zemlji. Osim kroz korištenje većeg broja jezika, višejezična komunikacija najlakše se ostvaruje slikama i simbolima koji su obično razumljivi većem broju ljudi, bez obzira na jezik kojim govore.

Uključivost se temelji na uvjerenju da su različitosti dio cjeline. Spoznaje o tome da je sve u našem okruženju visoko međuovisno i povezano, kao i spoznaje o tome da perspektive iz koje nešto promatramo mogu bitno utjecati na prikladnost odgovora, suvremene pojedince upućuju na poštovanje i uvažavanje različitosti. Ukoliko želite uspješno surađivati i komunicirati s pripadnicima 
različitih kultura, izuzetnojevažno da poštujetenjihovu kulturu, a timeinjihovestavoveipreferencije. U suvremenom društvu svima je dopušteno da budu drugačiji, dokle god ne narušavaju slobodu i sigurnost ostalih članova društva. Jedna od prvih kompanija u svijetu koja je počela primjenjivati multikulturalnu komunikacijsku (a time i prodajnu) strategiju jest talijanska tvrtka Benetton Group S.p.A. Ova tvrtka danas je jedan od najvećih modnih brendova, koja se bavi prodajom odjevnim predmeta u otprilike 5000 prodajnih mjesta širom svijeta (www.benettongroup.com). Kao što to napominje Kotarski (2019), u Europi primarni problem nije diskriminacija useljenika, već njihova samoizolacija. Da bi multikulturalna komunikacijska strategija ponudila sinergijske učinke nužno je da postoji iskrena obostrana želja za suradnjom i komunikacijom. U praksi se uključivost najbolje provodi kroz sudjelovanje u donošenju relevantnih političkih i poslovnih odluka, poput onih vezanih uz oblikovanje proizvoda i usluga, te kroz angažiranje članova različitih kultura u poslovanju organizacije.

Interaktivnost predstavlja proces (učinkovite) razmjene informacija između više različitih subjekata i objekata. Kada je podržana suvremenim informacijsko-komunikacijskim tehnologijama, digitalna interakcija omogućuje učinkovitu identifikaciju korisničkih zahtjeva i preferencija, a samim time jednostavniju multikulturalnu komunikaciju. Među osnovne zadaće učinkovite interakcije ubrajaju se jednostavnost razmjene informacija, sposobnost učinkovitog reagiranja na zahtjeve korisnika i personalizacija. Kreiranjem komunikacijskih kanalai poruka kojesu prilagođene različitim kulturnim skupinama, organizacije uspijevaju istovremeno komunicirati s većim brojem različitih skupina korisnika. lako je implementacija mobilnih aplikacija i ostalih interaktivnih tehnoloških rješenja koja omogućuju dinamičnu interakciju s korisnicima, zaposlenicima i suradnicima standardni dio komunikacijske strategije najuspješnijih poslovnih organizacija u svijetu, na našem tržištu još uvijek postoji veliki broj privatnih i javnih organizacija koje ne koriste takva interaktivna rješenja, a što znači da samim time i propuštaju prilike za komunikaciju i suradnju koje iz toga proizlaze. Osim kroz digitalne komunikacijske kanale, u kontekstu multikulturalnosti, interkativnost se ostvaruje i na sve ostale načine putem kojih je moguće komunicirati s ciljnom skupinom korisnika.

\section{ZAKLJUČAK}

Unatoč povremenim problemima do kojih interakcija s pripadnicima različitih kultura može dovesti, multikulturalizam zbližava ljude i obogaćuje njihovo iskustvo. Kad se komunikacija i suradnja među pripadnicima različitih kultura zasniva na kognitivnoj, emocionalnoj i osjećajnoj empatiji na temelju koje su sugovornici spremni prilagoditi vlastite komunikacijske obrasce, ne samo kroz korištenje višejezičnih i fokusiranih interaktivnih informacijsko komunikacijskih rješenja, već i na način da zaista teže uključivosti i suradnji, tada se kreira novi prostor za kreiranje sinergijskih učinaka u multikulturalnom okruženju. Multikulturalna komunikacijska strategija može se opisati kao „master ključ“ koji otvara više brava, od kojih svaka ima svoj vlastiti ključ. Glavni nedostatak multikulturalne komunikacijske strategije proizlazi iz toga što su pripadnici određenih kultura zatvoreniji, a time i manje spremni prakticirati fleksibilnost koja podrazumijeva ublažavanje odlika osobnog komunikacijskog stila. Unatoč tome što uvažava razlike, multikulturalizam uslijed snažne interakcije istovremeno i razgrađuje razlike među pojedincima te na taj način pogoduje obogaćivanju i promjeni svake kulture. 
Provedena analiza jasno upućuje na to da bi organizacije u Republici Hrvatskoj trebale što prije implementirati vlastite multikulturalne komunikacijske strategije, koje će u sinergiji s gospodarskim, demografskim i imigracijskim strategijama, te povezanim politikama, omogućiti unapređenje ekonomske stabilnosti i konkurentnosti hrvatskog gospodarstva. Pri definiranju imigracijske politike, svakako bi trebalo favorizirati profile stručnjaka koji trenutno nedostaju na tržištu i one koji će biti potrebni u budućnosti sukladno strategiji gospodarskog razvitka. Osim toga, menadžeri hrvatskih poduzeća trebali bi što je moguće prije krenuti s razvojem komunikacijskih i marketinških strategija kako bi se na vrijeme pripremili za izazove međunarodnih tržiš̌ta.

\section{REFERENCE}

Akrap, A. (2015) Demografski slom Hrvatske: Hrvatska do 2051. Bogoslovska smotra, 3, 855-868.

Al-Araki, M. (2015) Models of Intercultural Communication: Identities, Styles of Acculturation, and Premises for Enjoying the Company of One Another-Empirical Data From the Public Sector in Norway. SAGE Open, 5(2). doi: $10.1177 / 2158244015577795$

Arasaratnam, L. A. (2013) Intercultural communication competence. In A. Kurylo (Ed.), Intercultural communication: Representation and construction of culture (Chap 3, pp. 47-68). Los Angeles, CA: SAGE Publications.

Auwalu Issa, A., Yunusa, M., Garga, F. (2015) The Meaning and Theories of Intercultural Communication. Kano: Bayero University, Faculty Of Social And Management Sciences Department Of Mass Communications 10.13140/ RG.2.2.14026.36806. https://www.researchgate.net/publication/309155695_The_Meaning_and_Theories_of_ Intercultural_Communication (3.10.2020.)

Baldwin, J. R., Hunt, S. K. (2002) Information seeking behavior in intercultural and intergroup communication. Human Communication Research, 28, 272-286.

Blanchard, E., Karanasios, S., Dimitrova, V. (2013) A Conceptual Model of Intercultural Communication: Challenges, Development Method and Achievements. CEUR Workshop Proceedings. 1009. https://www.researchgate.net/ publication/261634281_A_Conceptual_Model_of_Intercultural_Communication_Challenges_Development_ Method_and_Achievements (20.10.2020.)

Culture Wizard (2016) Trends in Global Virtual Teams. Virtual Teams Survey Report - 2016. New York: RW3 Llc. http:// cdn.culturewizard.com/PDF/Trends_in_VT_Report_4-17-2016.pdf(10. 10. 2020.)

Dugonjić, A. (2018) Doprinos halala u razvoju turizma Republike Hrvatske. 8. Turistički forum - Kulturni turizam i perspektive razvoja religijskog turizma u Hrvatskoj. Stručni skup: Konferencija vjerskog turizma, sakralne baštine i hodočašća. https://www.hgk.hr/documents/008-aldin-dugonjic-doprinos-halala-u-razvoju-turizma-urh5bb8ffc599641.pdf (1. 10.2020.)

DZS (2020) MIGRACIJA STANOVNIŠTVA REPUBLIKE HRVATSKE U 2019. Priopćenje br. 7.1.2., Zagreb: Državni zavod za statistiku. https://www.dzs.hr/Hrv_Eng/publication/2020/07-01-02_01_2020.htm (8. 8. 2020.)

DZS (2019a) DOLASCI I NOĆENJA TURISTA U 2018. Priopćenje br. 4.3.2. Zagreb: Državni zavod za statistiku. https:// www.dzs.hr/Hrv_Eng/publication/2018/04-03-02_01_2018.htm (7.8. 2020.)

DZS (2019b) ROBNA RAZMJENA REPUBLIKE HRVATSKE S INOZEMSTVOM U 2018. KONAČNI PODACI. Priopćenje b.r. 4.2.2. https://www.dzs.hr/Hrv_Eng/publication/2019/04-02-02_01_2019.htm (1. 10. 2020.)

Gallup (2011) User language preferences online. Analytical report, Flash EB Series \#313. The Gallup Organization. https:// ec.europa.eu/commfrontoffice/publicopinion/flash/fl_313_en.pdf (10. 11. 2020.)

Giles. H., Ogay, T. (2007) Communication Accommodation Theory. In B. B. Whaley \& W. Samter (Eds.), Explaining communication: Contemporary theories and exemplars (pp. 293-310). Mahwah, NJ: Lawrence Erlbaum https:// core.ac.uk/download/pdf/147103741.pdf (20. 8. 2020.)

Hall, E. T. (1990) The silent language. New York: Anchor Books. 


\section{O. Rafajac, S. S. Washington: Multikulturalna komunikacijska strategija}

Zbornik Veleučilišta u Rijeci, Vol. 9 (2021), No. 1, pp. 249-265

HGK (2019) Demografski podaci po županijama. Zagreb: Hrvatska gospodarska komora https://www.hgk.hr/ documents/demografija-po-zupanijama-konacno5c41d3cf80bb7.pdf (1. 8. 2020.)

Jagić, S. (2006) Interkulturalno-pedagoški čimbenici turizma. PEDAGOGIJSKA istraživanja, 3 (1), 73 - 86. file:///C:/Users/ User/AppData/Local/Temp/SJhrv.pdf (30. 10. 2020.)

Kotarski, K. (15.12.2019) Multikulturalizam vs. asimilacija u zapadnim liberalnim društvima (II dio serije o globalnim migracijama). https://arhivanalitika.hr/blog/multikulturalizam-vs-asimilacija-u-zapadnim-liberalnim-drustvima-iidio-serije-o-globalnim-migracijama/ (20. 10. 2020.)

Kumbier, D., Schulz von Thun, F. (2009) Interkulturalna komunikacija: Metode, modeli, primjeri. Zagreb: Erudita

Lustig, M. W., Koester, J. (2007) Intercultural competence: interpersonal communication across cultures (5th ed.). Shanghai, China: Shanghai Foreign Language Education Press.

Mesić, M. (2006) Multikulturalizam: društveni i teorijski izazovi. Zagreb: Školska knjiga

MUP RH (2020) Stanje iskorištenosti godišnje kvote dozvola za boravak i rad po djelatnostima i zanimanjima koje su izdane sukladno Odluci Vlade RH. Zagreb: Ministarstvo unutarnjih poslova RH https://mup.gov.hr/gradjani-281562/ moji-dokumenti-281563/stranci-333/statistika-169019/169019 (01.09.2020.)

Perasović, B. (2002) Sociologija subkultura i hrvatski kontekst. Institut društvenih znanosti, Ivo Pilar, Zagreb, Društvena istraživanja, 11 (2-3), 485-498. https://hukzp.pravo.hr/_download/repository/9_Supkulture_ Perasovic.pdf (1. 10. 2020.)

Senge, P. M. (2010) The Fifth Discipline: The Art and Practice of the Learning Organization: First edition. London: Cornerstone Digital.

Shofner, K. (2020) 5 keys to effective multicultural communication. ULG'S LANGUAGE SOLUTIONS BLOG.

https://www.unitedlanguagegroup.com/blog/five-keys-to-effective-multicultural-communication (20. 10. 2020.)

Stričević, I. (2012) Multikulturalna pismenost u knjižnici - temelj interkulturalnog dijaloga. 8. savjetovanje za narodne knjižnice u Republici Hrvatskoj: Knjižnica, komunikacijsko i multikulturalno središte lokalne zajednice: zbornik radova (24), priredila za tisak Jelica Leščić. Zagreb: Nacionalna i sveučilišna knjižnica u Zagrebu, 257-268.

Stobierski, T. (12. studenog, 2019) How to improve cross-cultural communication in the workplace. https://www. northeastern.edu/graduate/blog/cross-cultural-communication/ (1. 9.2020)

Vlada RH (2014) Odluka o utvrđivanju godišnje kvote dozvola za zapošljavanje stranaca za kalendarsku godinu 2015. NN 151/2014. https://narodne-novine.nn.hr/clanci/sluzbeni/2014_12_151_2835.html (20.6. 2020.)

Vlada RH (2016a) Odluka o utvrđivanju godišnje kvote dozvola za zapošljavanje stranaca za kalendarsku godinu 2016. NN 39/2016. https://narodne-novine.nn.hr/clanci/sluzbeni/2016_04_39_1027.html (20.6. 2020.)

Vlada RH (2016b) Odluka o utvrđivanju godišnje kvote dozvola za zapošljavanje stranaca za kalendarsku godinu 2017. NN 118/2016. https://narodne-novine.nn.hr/clanci/sluzbeni/2016_12_118_2589.html (20. 6. 2020.)

Vlada RH (2017) Odluka o utvrđivanju godišnje kvote dozvola za zapošljavanje stranaca za kalendarsku godinu 2018. NN 122/2017. https://narodne-novine.nn.hr/clanci/sluzbeni/2017_12_122_2783.html (20 .6. 2020.)

Vlada RH (2018) Odluka o utvrđivanju godišnje kvote dozvola za zapošljavanje stranaca za kalendarsku godinu 2019. NN 116/2018. https://narodne-novine.nn.hr/clanci/sluzbeni/2018_12_116_2310.html (20.6. 2020.)

Wertheimer-Beletić, A. (1999) Stanovništvo i razvoj. Zagreb: Biblioteka gospodarska misao

Wiggins, B. E. (2012) Toward a model for intercultural communication in simulations. Simulation \& Gaming, 43, 550-572. doi:10.1177/1046878111414486

Zebec, M. (2016) Kulturološke razlike u poslovnoj komunikaciji. Diplomski rad br.32/OJ/2016, Varaždin: Sveučilište sjever, Sveučilišni centar Varaždin, Studij Odnosi s javnostima. https://zir.nsk.hr/islandora/object/unin:744/ preview (1. 5. 2020.)

http://www.benettongroup.com/the-group/profile/at-a-glance/ 


\title{
MULTICULTURAL COMMUNICATION STRATEGY
}

\author{
Ozren Rafajac \\ PhD, Assistant Professor, Polytechnic of Rijeka, Vukovarska 58, 51000 Rijeka, Croatia; \\ e-mail: ozren.rafajac@gmail.com \\ Sara Shanice Washington \\ Bacc. oec., Student, Polytechnic of Rijeka, Vukovarska 58, 51000 Rijeka, Croatia; \\ e-mail: zasaru.wash@gmail.com
}

\begin{abstract}
This paper provides guidelines for the implementation of the multicultural communication strategy, and emphasizes its significance for the development of public and private organizations in the Republic of Croatia. The analysis of migration, tourism and export trends clearly indicates a strong need for the multicultural communication strategy among Croatian organizations. The multicultural communication strategy is a communication framework that enables the simultaneous and effective interaction between individuals with different cultural backgrounds. This strategy can be described as the master key that opens a set of locks, each of which also has its own key. Multicultural communication strategy relies primarily on convergent communication activities. In the implementation stage it is recommended to follow six basic guidelines: empathy, flexibility, focus, multilingualism, inclusiveness and interactivity. Empathy implies understanding, which can be enhanced by asking in-depth questions and listening actively. Flexibility implies the ability to adapt, which is achieved through minimizing personal bias. Focusing means empowering conversations that facilitate collaboration. Multilingualism is most easily realized by images and symbols that are understandable to a wider audience regardless of the language being spoken or cultural aspects. Inclusiveness is most often implemented through participation in relevant political and business decisions. Apart from digital communication channels, interactivity is realized in ways through which the target group of users can exchange information. Multicultural communication is most easily conducted in situations where there is a mutual need for cooperation and understanding. In addition, multicultural communication strategy is particularly needed in the public sector areas such as transport, health, education, legislation and public administration.
\end{abstract}

Key words: business communication, multiculturalism, interculturality, multicultural communication strategy 
